\title{
Region-related risk factors for respiratory symptoms in European and Californian farmers
}

\author{
E. Monsó*, M. Schenker", K. Radon ${ }^{\ddagger}$, E. Riu*, R. Magarolas ${ }^{+}$, S. McCurdy \\ B. Danuser ${ }^{\S}$, M. Iversen ${ }^{f}$, C. Saiki ${ }^{\#}$, D. Nowak
}

Region-related risk factors for respiratory symptoms in European and Californian farmers. E. Monsó, M. Schenker, K. Radon, E. Riu, R. Magarolas, S. McCurdy, B. Danuser, M. Iversen, C. Saiki, D. Nowak. (C) ERS Journals Ltd 2003.

ABSTRACT: The aim of this study was to determine the prevalences and regional risk factors for respiratory symptoms in European and Californian farmers.

Farmers participating in the 1993-1997 surveys performed in Europe $(n=7,188)$ and California $(n=1,839)$ were included in this cross-sectional study. Respiratory symptoms and farming characteristics were assessed by questionnaire and risk factors associated with symptoms using logistic regression.

The prevalences of rhinitis and asthma were lower in European $(12.7 \%$ and $2.8 \%)$ than in Californian farmers $(23.9 \%$ and $4.7 \%)$, but chronic bronchitis and toxic pneumonitis were more prevalent in Europe $(10.7 \%$ and $12.2 \%)$ than in California $(4.4 \%$ and $2.7 \%)$. Respiratory symptoms were associated with poultry and rabbit farming, flower growing and the cultivation of grain and oil plants. Working in Europe was a statistically significant risk factor for chronic bronchitis and toxic pneumonitis. Chronic bronchitis was related to toxic pneumonitis, work inside confinement buildings and greenhouses.

Chronic bronchitis and toxic pneumonitis are highly prevalent among European farmers and are mainly attributable to indoor work.

Eur Respir J 2003; 21: 323-331.
*Dept of Pneumology, Hospital Germans Trias i Pujol, Badalona, Catalonia, Spain. " Dept of Epidemiology and Preventive Medicine, University of California, Davis, CA, USA. "Institute and Outpatient Clinic for Occupational and Environmental Medicine, Faculty of Medicine, Ludwing Maximilians University, Munich, Germany. ${ }^{+}$Hospital Mare Deu de la Salut, Tarragona, Catalonia, Spain. ${ }^{\S}$ Institute of Hygiene and Occupational Physiology, Zürich, Switzerland. ${ }^{f}$ University Hospital, Aarhus, Denmark.

Correspondence: E. Monsó, Servei de Pneumologia, Hospital Germans Trias i Pujol, Carretera de Canyet s/n, 08916 Badalona, Catalonia, Spain. Fax: 34934978843

E-mail: emonso@ns.hugtip.scs.es

Keywords: Chronic bronchitis, confinement building, farming, greenhouse, toxic pneumonitis, respiratory symptoms

Received: August 62002

Accepted after revision: October 32002

This study was supported by the European Union (BMH1-CT94-1554), by the Fondo de Investigaciones Sanitarias (99/1022) and the Fundació Catalana de Pneumologia.
Farming has often been related to respiratory symptoms and high prevalences of bronchial asthma and chronic bronchitis have been reported both in animal and crop farmers [1-8]. For farmers exposed to livestock, the pathogenetic role of gases, dusts and aeroallergens from mammals, poultry, insects and mites has been well characterised [9]. For crop farmers, symptoms have been related to exposure to a variety of agents present in agricultural settings, among them pollens, grain dust, mites, moulds and endotoxin $[10,11]$. When farmers have been compared to nonfarming control populations from the same regions, an increased prevalence of respiratory symptoms has been commonly observed [12-15], but studies of the prevalence of respiratory symptoms in different farming regions have revealed great geographical variability [16-18]. Such differences may be related to sociodemographical factors, self-selection
$[19,20]$, type of farming predominantly practiced in the region, or to local characteristics of farming.

The present comparative analysis of respiratory symptoms in European and Californian farmers was performed to determine the prevalence of rhinitis, asthma, chronic bronchitis and toxic pneumonitis in the two regions, and to assess the impact of the types of farming and the regional characteristics of production on the prevalence of these respiratory symptoms.

\section{Methods}

Design

A cross-sectional study of the prevalence of respiratory symptoms and occupational exposures in European and Californian animal and/or crop farmers 
was performed. The European sample consisted of all farmers who participated in the European Union Concerted Action "Prevalence and risk factors for airway obstruction in farmers", recruited in 1995-1997 $[2,21,22]$. The Californian sample included all participants in the University of California, Davis Farmer Health Study, recruited in 1993 [23, 24].

\section{Population}

Altogether, 7,674 farmers from four countries (Denmark, Germany, Switzerland and Spain) participated in the European study and 1,947 farmers took part in the Californian study. The population sample in each region was selected at random from the most recent available census record. Individuals were contacted by mail, phone or home visits and asked to fill out a self-administered questionnaire on respiratory symptoms and occupational characteristics. The response rates were $85.3 \%$ in Europe and $80.4 \%$ in California. Details of the enrolment procedure for the two studies have been reported elsewhere [2, 22-24]. All workers involved in one or more of the main types of animal (pig, beef/veal, dairy, poultry, sheep and rabbit) or crop farming (grain, vegetables, tomatoes, root crops, oil-producing plants, fruit/berries, nuts, rice, cotton or flowers) from both samples were included in the present analysis (Europe: $n=7,188$; California: $\mathrm{n}=1,839$ ).

\section{Questionnaire}

Self-administered questionnaires were used in both studies. The symptom section of each questionnaire included questions on age, sex, smoking and respiratory symptoms (wheezing, rhinitis, asthma and chronic bronchitis). For the European study these questions were obtained from the European Community Respiratory Health Survey (ECRHS) questionnaire [25, 26], while the questions for the Californian study were adapted from the American Thoracic Society questionnaire [27]. In addition, the symptoms section included a question on symptoms suggesting toxic pneumonitis. The occupational section of the questionnaires assessed the exposures at work, asking the subject if their occupation involved livestock and/ or the cultivation of plants, type of animals and/or plants produced and, in the European questionnaire, work inside confinement buildings or greenhouses. In both questionnaires, these items were adapted from a validated questionnaire evaluating organic dust exposure [28].

Only items using the same wording in both questionnaires were considered for the present study. Age, sex, smoking (never, former, current), prevalence of rhinitis or asthma in the last year, chronic bronchitis (phlegm $>3$ months each yr) and toxic pneumonitis (flu-like symptoms such as fever, chills, muscle ache, weakness, headache, cough, chest tightness or shortness of breath 2-6 h after dust exposure) were analysed in the symptoms section. In the occupational section, animals raised (pig, beef/veal, dairy, poultry, sheep or rabbit farming) and crops cultivated (grain, vegetables, tomatoes, root crops, oil-producing plants, fruit/berries, nuts, rice, cotton or flowers) were considered.

\section{Indoor work}

Questions on work inside confinement buildings or greenhouses were used for the assessment of indoor work as a risk factor for chronic bronchitis in the subsample of European farmers. For the assessment of the relationship between chronic bronchitis and the exposure to indoor air contaminants in nonsmokers, a representative sample of European animal farmers working inside confinement buildings was selected $(n=112)$ and environmental measurements were performed in the workplace. Area $\left(\mathrm{m}^{2}\right)$, temperature $\left({ }^{\circ} \mathrm{C}\right)$, humidity $(\%)$, air velocity $\left(\mathrm{m} \cdot \mathrm{s}^{-1}\right)$, carbon dioxide (parts per million (ppm)) and ammonia (ppm) in the confinement building were determined and every subject's exposure to total dust $\left(\mathrm{mg} \cdot \mathrm{m}^{-3}\right)$ and endotoxin $\left(\mathrm{ng} \cdot \mathrm{m}^{-3}\right)$ was measured using a personal pump. Details of the selection procedure of this subsample and the methodology used for the environmental measurements have been reported elsewhere [29, 30].

\section{Statistical analysis}

Descriptive analyses were performed after regional stratification and given as proportions, means with SD or medians with interquartile ranges when appropriate. The Chi-squared distribution was used to compare the prevalence of respiratory symptoms in the two regions and an unpaired t-test was used to compare continuous variables. The associations among symptoms, occupation, region and indoor air contaminants were assessed using univariate and multivariate logistic regression models, with respiratory symptoms as the dependent variable. All variables that showed an association $(\mathrm{p}<0.25)$ with the outcome variable in the univariate model were entered in the multivariate model and the most parsimonious model that still explained the data was accepted as the final model [31]. First, to assess type of farming as a risk factor for respiratory symptoms, an occupational model was created for every respiratory symptom, with livestock raised (categorised as pig, beef/veal, dairy, poultry, sheep or rabbit) and cultivated crop (categorised as grain, vegetables, tomatoes, root crops, oil-producing plants, fruit/berries, nuts or flowers) as the independent variables, with adjustment for potential sociodemographical confounders (age, sex, former and current smoking). The impact of each type of farming on the outcome was determined with nonexposed farmers as the reference. Second, to analyse the potential relationship between farming region and respiratory symptoms, multivariate models were created with region as the independent variable, adjusting the models for sociodemographical confounders and country in a first step, and for these variables and the types of farming included in the occupational model in a second step. Adjustment for 
Table 1.-Sociodemographical characteristics and symptoms in farmers

\begin{tabular}{lccc}
\hline & Europe & California & p-value \\
\hline Sociodemographical characteristics & & & \\
$\quad$ Number of subjects & 7188 & 1839 & $<0.001$ \\
Age mean \pm SD & $48.0 \pm 13.2$ & $55.3 \pm 13.4$ & $<0.001$ \\
Sex (females) & $1246(17.3)$ & $181(9.8)$ & $<0.001$ \\
Smoking & $1329(18.5)$ & $600(32.6)$ & $<0.001$ \\
$\quad$ Former & $1602(22.3)$ & $212(11.5)$ & $<0.001$ \\
$\quad$ Current & $910(12.7)$ & $440(23.9)$ & $<0.001$ \\
Respiratory symptoms last year & $203(2.8)$ & $86(4.7)$ & $<0.001$ \\
Rhinitis & $770(10.7)$ & $80(4.4)$ & $<0.001$ \\
Asthma & $877(12.2)$ & $50(2.7)$ & \\
Chronic bronchitis & & \\
Toxic pneumonitis &
\end{tabular}

Data are presented as n (\%) unless otherwise stated.

country in these multivariate analyses was accomplished using dummy variables. Smoking was assessed as an interaction variable in the models, to check for an effect modification. Finally, to assess the impact of indoor work on the prevalence of symptoms, the association between chronic bronchitis and toxic pneumonitis, working inside confinement buildings or greenhouses and indoor air contaminant exposure were analysed following the same methodology. Results were given as odds ratios (OR), with 95\% confidence intervals $(95 \% \mathrm{CI})$. All statistical tests were two sided and a p-value of $<0.05$ was reported as statistically significant.

\section{Results}

\section{Respiratory symptoms and occupational exposures}

Table 1 shows the prevalences of respiratory symptoms. Rhinitis and asthma were more prevalent in Californian (23.9\% and $4.7 \%$, respectively) than in European farmers $(12.7 \%$ and $2.8 \%)(p<0.001)$, but the prevalences of chronic bronchitis and toxic pneumonitis were higher in Europe (10.7\% and 12.7\%) than in California $(4.4 \%$ and $2.7 \%)(p<0.001)$. The prevalences of the different types of animal and crop farming in the two regions were also different. Pig and dairy farming predominated in Europe but were uncommon in California. Grain, root and oilproducing plants were the main European crops, whereas fruit/berries and nuts were the most common ones in California (table 2).

\section{Occupational risk factors}

To define a specific occupational model for every respiratory symptom, the different types of farming were assessed as risk factors for rhinitis, asthma, chronic bronchitis and toxic pneumonitis, with adjustment for sociodemographical characteristics. Poultry and rabbit farming, flower growing and the cultivation of grain and oil-producing plants were the most clinically relevant occupational exposures, all of them appearing as statistically significant risk factors for more than one respiratory symptom in the defined models (table 3 ).

\section{Region-related risk factors}

To determine the impact of regional farming characteristics on the prevalence of respiratory symptoms and their relationship with the high prevalence of rhinitis and asthma in Californian farmers and chronic bronchitis and toxic pneumonitis in Europeans, multivariable analyses were performed. Because a statistically significant interaction between region and smoking was found in the multivariate model with chronic bronchitis as the dependent variable (OR 0.37 , 95\% CI $0.22-0.64$ ), the following multivariate analyses were performed after stratification for smoking.

For nonsmokers, working in Europe emerged as a relevant risk reduction factor for rhinitis and asthma in the univariate analysis. The risk of rhinitis continued to be significantly lower for European

Table 2.-Regional farming characteristics

\begin{tabular}{lcr}
\hline & Europe & California \\
\hline Animal exposure & & \\
Swine & $2337(32.5)$ & $40(2.2)$ \\
Beef/veal & $3987(55.5)$ & $381(20.7)$ \\
Dairy & $4037(56.2)$ & $136(7.4)$ \\
Poultry & $692(9.6)$ & $89(4.8)$ \\
Sheep & $522(7.3)$ & $105(5.7)$ \\
Rabbit & $212(2.9)$ & $8(0.4)$ \\
One or more & $6009(83.6)$ & $584(31.8)$ \\
Crop exposure & & \\
Grain & $3754(52.2)$ & $180(9.8)$ \\
Vegetables & $943(13.1)$ & $63(3.4)$ \\
Tomatoes & $516(7.2)$ & $82(4.5)$ \\
Root crops & $1801(25.1)$ & $59(3.2)$ \\
Oil plants & $1235(17.2)$ & $47(2.6)$ \\
Fruits/berries & $563(7.8)$ & $878(47.7)$ \\
Nuts & $287(4.0)$ & $490(26.6)$ \\
Flowers & $311(4.3)$ & $89(4.8)$ \\
Rice & $0(0.0)$ & $54(2.9)$ \\
Cotton & $0(0.0)$ & $81(4.4)$ \\
One or more & $4597(64.0)$ & $1487(80.9)$ \\
\hline
\end{tabular}

Data are presented as n (\%). 
Table 3. - Type of farming as a risk factor for respiratory symptoms

\begin{tabular}{|c|c|c|c|c|}
\hline & Rhinitis & Asthma & Chronic bronchitis & Toxic pneumonitis \\
\hline \multicolumn{5}{|c|}{ Livestock farming } \\
\hline Swine & $0.65(0.56-0.76)$ & & $1.22(1.03-1.43)$ & \\
\hline Beef/veal & $1.13(0.97-1.31)$ & & & $0.76(0.64-0.90)$ \\
\hline Dairy & $0.55(0.47-0.64)$ & $0.80(0.62-1.03)$ & & $1.32(1.11-1.57)$ \\
\hline Poultry & $1.30(1.06-1.60)$ & $1.90(1.34-2.68)$ & & $1.25(0.99-1.59)$ \\
\hline Sheep & & & $1.27(0.98-1.66)$ & $1.31(1.01-1.69)$ \\
\hline Rabbit & $1.27(0.88-1.85)$ & & $1.68(1.13-2.50)$ & $1.89(1.30-2.75)$ \\
\hline \multicolumn{5}{|l|}{ Crop farming } \\
\hline Grain & $1.13(1.00-1.29)$ & & $1.42(1.21-1.67)$ & $2.15(1.82-2.53)$ \\
\hline Vegetables & $0.77(0.61-0.97)$ & $0.52(0.32-0.83)$ & & \\
\hline Tomatoes & $0.77(0.57-1.04)$ & & & \\
\hline Root crops & & $1.28(0.94-1.75)$ & & $1.51(1.28-1.77)$ \\
\hline Oil plants & & & $1.49(1.22-1.81)$ & 1.66 (1.39-1.98) \\
\hline Fruit/berries & $1.30(1.10-1.54)$ & & $0.90(0.72-1.12)$ & $0.81(0.64-1.01)$ \\
\hline Nuts & $1.23(1.00-1.51)$ & & $0.55(0.40-0.77)$ & \\
\hline Flowers & $1.29(0.98-1.70)$ & $1.71(1.06-2.77)$ & $1.67(1.22-2.27)$ & $1.75(1.29-2.38)$ \\
\hline Cotton & 1.77 (1.08-2.89) & & $0.14(0.02-1.01)$ & \\
\hline Rice & & & & $0.03(0.00-9.58)$ \\
\hline
\end{tabular}

Data are presented as adjusted odds ratio (95\% confidence interval), adjusted for age, sex, former smoking, current smoking, animal and crop exposures $(\mathrm{p}<0.25)$, using nonexposed farmers as the reference for every animal and crop exposure. $\mathrm{n}=9027$.

farmers after adjustment for sociodemographical confounders and types of farming in the defined occupational model (OR 0.58, 95\% CI 0.47-0.71). The low prevalence of asthma among European farmers emerged as dependent on the regional sociodemographical characteristics of the workforce, given that asthma was not significantly associated with farming region after adjustment for sociodemographical confounders $(0.96,0.68-1.35)$ and the adjustment for the types of farming in the occupational model did not modify the results (OR $0.95,95 \%$ CI $0.67-1.35$ ). In smokers, rhinitis and asthma were not significantly associated with farming region in the adjusted models (table 4). Hence, the high prevalence of rhinitis in Californian farmers must be considered to be unrelated to the sociodemographical factors of the workforce or to the type of farming practiced in that region. Rhinitis should rather be assumed to be associated with regional factors not measured in the present study.

Working in Europe emerged as a relevant risk factor for chronic bronchitis in the univariate analysis and similar associations were found for toxic pneumonitis (table 4). The association between chronic bronchitis and farming in Europe continued to be statistically significant after adjustment for the sociodemographical confounders, both for nonsmokers (OR 4.19, 95\% CI 3.08-5.70) and smokers (OR 2.82, $95 \%$ CI 1.76-4.53). The adjustment of the models for types of farming only slightly decreased the strength of the association between chronic bronchitis and working in Europe, both for nonsmokers (OR 3.61, 95\% CI 2.64-4.95) and smokers (OR 1.73, 95\% CI 1.05-2.86), suggesting that the high prevalence of chronic bronchitis in European farmers depends only partly on the type of animals and crops produced in the region that other regional determinants must be advocated to explain the high prevalence of chronic bronchitis in European farmers.

\section{Chronic bronchitis and indoor work}

To explore the hypothesis that the high prevalence of chronic bronchitis in Europe may be related to indoor farming, the association between this respiratory symptom, toxic pneumonitis, work inside confinement buildings and greenhouses was examined, including these variables in the previously defined multivariable models in which chronic bronchitis was the dependent variable. These analyses were only performed in the subsample of European farmers, because information about indoor work was not available from Californian farmers. In the studied population the prevalence of chronic bronchitis was $>25 \%$ when toxic pneumonitis was reported, both in nonsmokers and smokers. Toxic pneumonitis was significantly associated with chronic bronchitis after adjustment for sociodemographical confounders and the types of farming in the occupational model, confirming the close relationship between both respiratory conditions (table 5).

Livestock farming inside confinement buildings was practiced by 3,716 out of the 7,188 European farmers $(51.7 \%)$ and greenhouse cultivation was reported by $239(3.3 \%)$. After adjustment for sociodemographical confounders and types of farming in the occupational model, working inside animal confinement buildings emerged as a statistically significant risk factor for chronic bronchitis, both in nonsmokers (OR 1.58, 95\% CI 1.27-1.96) and smokers (OR 1.98, 95\% CI 1.46-2.68). A similar association was found between working with crops inside greenhouses and chronic bronchitis, but only for nonsmokers (OR 1.59, 95\% CI 1.02-2.48) (table 5).

For the assessment of the impact of animal confinement building characteristics in the prevalence of chronic bronchitis in nonsmoking European farmers, indoor air contaminants were measured in a representative subsample of the studied farmers (table 6) 


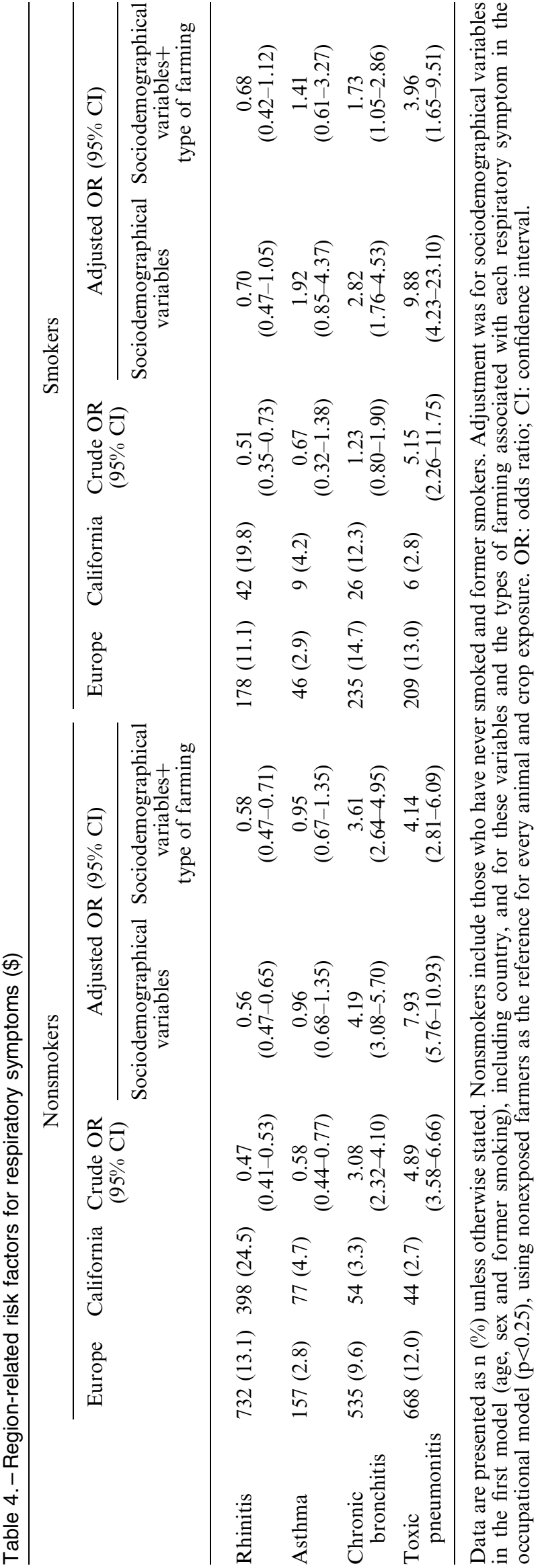

Table 5.-Association of chronic bronchitis with toxic pneumonitis and indoor work

Chronic bronchitis

Toxic pneumonitis

Reported

Nonsmokers

Smokers

Not reported

Nonsmoker

Smoker

Crude OR $(95 \% \mathrm{CI})$

Nonsmoker

Smoker

Adjusted OR (95\% CI)

Nonsmoker

Smoker

$188(28.1)$

$83(39.7)$

$347(7.1)$

$152(10.9)$

$5.16(4.22-6.31)$

$5.38(3.89-7.44)$

$5.17(4.21-6.34)$

$4.28(3.01-6.10)$

Work inside animal

confinement building

Reported

Nonsmokers

Smokers

Not reported

Nonsmokers

Smokers

Crude OR $(95 \% \mathrm{CI})$

Nonsmokers

Smokers

Adjusted OR (95\% CI)

Nonsmokers

Smokers

Work inside greenhouse

Reported

Nonsmokers

Smokers

Not reported

Nonsmokers

Smokers

Crude OR $(95 \%$ CI)

Nonsmokers

Smokers

Adjusted OR (95\% CI)

Nonsmokers

Smokers

$324(11.2)$

153 (18.5)

$211(7.8)$

$82(10.6)$

$1.49(1.24-1.79)$

$1.91(1.43-2.54)$

$1.58(1.27-1.96)$

$1.98(1.46-2.68)$

27 (15.2)

9 (14.4)

$508(9.4)$

$226(14.7)$

$1.72(1.13-2.62)$

$1.01(0.49-2.07)$

$1.59(1.02-2.48)$

$0.98(0.45-2.12)$

Data are presented as $\mathrm{n}(\%)$ unless otherwise indicated. Data for European farmers only. Nonsmokers include those who have never smoked and former smokers. Adjustment for country, age, sex, former smoking and types of farming in the occupational model $(\mathrm{p}<0.25)$, using nonexposed farmers as the reference for every animal and crop exposure. CI: confidence interval; OR: odds ratio.

and were included in the occupational model created for that respiratory symptom. After adjustment for covariates, farming in small confinement buildings (area building: OR $0.31,95 \%$ CI $0.11-0.89$ ) and indoor exposure to high concentrations of total dust (OR 4.07, 95\% CI 1.40-11.80) emerged as statistically significant risk factors for chronic bronchitis in nonsmokers (table 7).

\section{Discussion}

The present cross-sectional study assessed the prevalence of respiratory symptoms in a sample of European and Californian animal and crop farmers, 
Table 6.-Characteristics of chronic bronchitis in nonsmoking European farmers"

\begin{tabular}{lc}
\hline Sociodemographical characteristics & \\
Age m SD & $44.7(10.9)$ \\
Sex females & $23(20.5)$ \\
Former smoking & $28(25.0)$ \\
Country & $31(27.7)$ \\
$\quad$ Denmark & $50(44.6)$ \\
Germany & $23(20.5)$ \\
Switzerland & $8(7.1)$ \\
Spain & $36(32.1)$ \\
Chronic bronchitis & $6(5.4)$ \\
In former smokers & $30(26.8)$ \\
In never-smokers & $11(10.7)$ \\
Chronic bronchitis + COPD & $3(11.1)$ \\
In former smokers & $8(10.5)$ \\
In never-smokers & \\
Type of farming & $84(75.0)$ \\
Swine & $27(24.1)$ \\
Beef/veal & $18(16.1)$ \\
Dairy & $36(32.1)$ \\
Poultry & \\
Confinement building characteristics & \\
Area $\cdot \mathrm{m}^{2}$ & $190.5(119.9-272.7)$ \\
Temperature ${ }^{\circ} \mathrm{C}$ & $18.3(15.8-20.5)$ \\
Humidity $\%$ & $77.1(71.1-84.4)$ \\
Air velocity $\mathrm{m}^{-1} \mathrm{~s}^{-1}$ & $0.12(0.00-0.21)$ \\
CO ${ }_{2}$ ppm & $1300(1000-1975)$ \\
Ammonia ppm & $8(5.7-15)$ \\
Total dust $\mathrm{mg} \cdot \mathrm{m}^{-3}$ & $5.0(2.5-8.3)$ \\
Endotoxin ng $\cdot \mathrm{m}^{-3}$ & $78.3(30.0-266.0)$ \\
\hline Data &
\end{tabular}

Data are presented as $\mathrm{n}(\%)$ unless otherwise indicated. $\mathrm{CO}_{2}$ : carbon dioxide; ppm: parts per million. ${ }^{\#}$ : only nonsmoking (never and former) European animal farmers included in the analysis $(\mathrm{n}=112)$; : lung function available from 103 subjects; ${ }^{+}$: median (interquartile range). Chronic obstructive pulmonary disease (COPD) defined according to the Global Initiative for Chronic Obstructive Lung Disease (GOLD) criteria [32].

and analysed the impact of regional farming characteristics on these symptoms. The most clinically relevant occupational exposures were poultry and rabbit farming, flower growing and the cultivation of grain and oilproducing plants, all of which were risk factors for more than one respiratory symptom. Rhinitis and asthma were more prevalent in Californian farmers and chronic bronchitis and toxic pneumonitis in Europeans. After adjustment for sociodemographical characteristics and types of farming, working in Europe persisted as a risk factor for chronic bronchitis and toxic pneumonitis, both in nonsmokers and smokers, confirming that the high prevalence of these respiratory symptoms in European farmers was independent of smoking and only partly related to the regional farm production. The close associations between chronic bronchitis and work inside confinement buildings and greenhouses suggest that the high prevalence of chronic bronchitis in European farmers is partly attributable to indoor work with either animals or crops, and high dust exposure together with work inside small confinement buildings were shown to be important risk factors for this symptom.

Respiratory symptoms well above the prevalences found in the general population have been observed in selected populations of farmers. Different studies in animal farmers have reported chronic bronchitis in almost one quarter, and asthma in $>5 \%$ of the workforce [12, 33-35]. In crop farmers, a recent French study found a $10 \%$ prevalence of chronic bronchitis in farmers cultivating cereals, twice the level in a control population from the same region [36] and a similar prevalence was found by VERGNENEGRE et al. [37]. Similarly, GAMSKY et al. [38] detected an increase in respiratory symptoms in Californian crop workers. Previous analyses of the European subsample in the present study demonstrated flower growing to be a risk factor for asthma and, further, showed that the cultivation of oil-producing plants increases the risk of chronic bronchitis [22, 39].

In the present study, poultry farming was found to be the only statistically significant animal exposure associated with asthma, an observation that agrees with previous reports in selected populations. KimBeLL-DunN et al. [40] reported that the observed $17 \%$ asthma prevalence among New Zealand poultry farmers was much higher than the prevalence among other animal farmers working in the same region. Occupational asthma related to sensitisation to avian aeroallergens and storage mites in the workplace has

Table 7. - Chronic bronchitis in nonsmokers and indoor contaminants

\begin{tabular}{|c|c|c|c|c|}
\hline \multirow[t]{3}{*}{ Greenhouse characteristics } & \multicolumn{4}{|c|}{ Chronic bronchitis } \\
\hline & \multicolumn{2}{|c|}{ Measurement } & \multirow[t]{2}{*}{ Crude OR $(95 \% \mathrm{CI})$} & \multirow[t]{2}{*}{ Adjusted OR $(95 \% \mathrm{CI})$} \\
\hline & Over median & Under median & & \\
\hline Area $\mathrm{m}^{2}$ & $10(17.8)$ & $26(46.4)$ & $0.25(0.10-0.59)$ & $0.31(0.11-0.89)$ \\
\hline Temperature ${ }^{\circ} \mathrm{C}$ & $18(32.1)$ & $18(32.1)$ & $1.00(0.45-2.21)$ & \\
\hline Humidity \% & $21(37.5)$ & $15(26.8)$ & $1.64(0.74-3.65)$ & \\
\hline Air velocity $\mathrm{m} \cdot \mathrm{s}^{-1}$ & $17(30.9)$ & $18(31.6)$ & $0.99(0.45-2.22)$ & \\
\hline $\mathrm{CO}_{2} \mathrm{ppm}$ & $18(32.1)$ & $17(30.4)$ & $1.12(0.50-2.49)$ & \\
\hline Ammonia ppm & $21(38.9)$ & $15(27.9)$ & $1.82(0.82-4.07)$ & \\
\hline Total dust $\mathrm{mg} \cdot \mathrm{m}^{-3}$ & $23(41.1)$ & $13(23.2)$ & $2.30(1.02-5.22)$ & $4.07(1.40-11.80)$ \\
\hline Endotoxin $\mathrm{ng} \cdot \mathrm{m}^{-3}$ & $20(35.7)$ & $16(28.6)$ & $1.39(0.63-3.08)$ & \\
\hline
\end{tabular}

Multivariate analysis adjusted for age, sex, former smoking, country and types of farming $(\mathrm{p}<0.25)$, using nonexposed farmers as the reference for every animal and crop exposure. OR: odds ration; CI: confidence interval; ppm: parts per million. ${ }^{\#}$ : nonsmoking (never and former) European animal farmers included in the analysis $(n=112)$. 
been diagnosed in poultry workers, and such sensitisation probably helps to explain the high prevalence of respiratory symptoms in these workers [30, 41-43]. The only type of crop farming significantly related to asthma in this study has been flower growing, consistent with a previous analysis performed in the European subsample [22]. Occasional cases of occupational asthma in flower growers have been described [44, 45] and sensitisation was attributed to moulds and flower allergens [39].

In the current study, the slightly higher prevalence of asthma in Californian $(4.7 \%)$ than in European farmers $(2.8 \%)$ was unrelated to the type of farming practiced in each region, given that poultry farming and flower growing, the occupational exposures that emerged as related to asthma, were not more prevalent in California. The authors interpret the high asthma prevalence in Californian farmers to be related to sociodemographical characteristics of the farming workforce of the region, given that region was no longer a significant risk factor for asthma after adjustment for such variables, either in nonsmokers or smokers. However, the high prevalence of rhinitis in Californian farmers $(23.9 \%)$ was unrelated to either sociodemographical factors or type of farming practiced in the region. Working in Europe persisted as a risk reduction factor for rhinitis after the adjustment for confounders, and it was statistically significant in nonsmokers and marginally significant in smokers. It may be hypothesised that this regional effect on the prevalence of rhinitis may depend on differences in farming procedures that lead to greater allergen exposure in California. Patterns in the regional prevalence of rhinitis, however, do not support this hypothesis. The western portion of the USA has a prevalence of rhinitis well above the $21 \%$ median found in the ECRHS $[45,46]$, and a high prevalence of rhinitis has been reported for Western North America [47]. These observations suggest that rhinitis in Californian farmers perhaps does not depend on regional farming characteristics but rather on environmental factors.

In the present study, chronic bronchitis was associated with pig and rabbit farming and with the cultivation of grain, oil-producing plants and flowers. However, the high prevalence of chronic bronchitis found in European farmers only partly depended on the high percentages of European farmers working with pigs and oil-producing plants and did not depend on the high prevalence of current smoking in Europe. Thus, after stratification according to smoking and adjustment for sociodemographical factors and the type of animal and/or crop produced, farming in Europe persisted as a statistically significant risk factor for chronic bronchitis both in nonsmokers and smokers. This observed regional effect must be considered to be occupation-related, and consistent with the high prevalence of chronic bronchitis reported for nonsmoking farmers in comparison with nonsmokers in the general European population [2]. The 3\% prevalence of chronic bronchitis found in nonsmoking Californian farmers, despite of the high frequency of former smokers $(32.6 \%)$ among them, is similar to the prevalence found in nonsmokers from the European general population [48] and supports this hypothesis.
In contrast, the $10 \%$ prevalence of chronic bronchitis found in nonsmoking European farmers is very high. A recent re-analysis of the ECRHS data is consistent with the present results, pointing to crop farming as a risk factor for chronic bronchitis in nonsmokers [49], and similar observations have been reported in selected populations of European animal farmers [50, 51].

In the current study, chronic bronchitis emerged as closely related to toxic pneumonitis, both in nonsmokers and smokers. Chronic bronchitis was reported by more than one quarter of the farmers reporting episodes of toxic pneumonitis, but was unusual in nonsmoking farmers without toxic pneumonitis. CARVAlHEIRO et al. [52] have also reported a similar association between chronic bronchitis and toxic pneumonitis in nonsmoking animal farmers. DALPHIN et al. [53] found that toxic pneumonitis preceded chronic bronchitis in 17 nonsmoking French dairy farmers, suggesting that toxic pneumonitis may in fact be a risk factor for chronic bronchitis. Toxic pneumonitis, considered a self-limiting disease that rarely persists beyond $36 \mathrm{~h}$, is characterised by influenza-like symptoms. Indoor handling of animal and/or vegetal products has been implicated in the appearance of the disease. The observed association between toxic pneumonitis and chronic bronchitis suggests that the pathogenesis of the latter may also be related to exposure to indoor air contaminants. Supporting this hypothesis, working inside confinement buildings emerged as a risk factor for chronic bronchitis in the present study, both for nonsmokers and smokers, and the prevalence of this respiratory symptom in nonsmoking animal farmers was related to high indoor dust exposure and working in small workplaces. Cormier et al. [54] also found that the high prevalence of chronic bronchitis in Canadian pig farmers was related to indoor work. In the present study, chronic bronchitis was additionally related to work inside greenhouses in nonsmoking farmers, a finding suggesting that the effect of indoor exposure to air contaminants on respiratory symptoms may not be limited to animal farmers. The data confirms that the high prevalence of chronic bronchitis in European farmers depends partly on indoor work as a regional farming characteristic. However, a role for other risk factors not assessed in the present study in the pathogenesis of chronic bronchitis in European farmers, such as storage procedures, altitude or regional harvesting practices, cannot be discarded [55-57]. Notwithstanding, the high prevalence of confinement building animal production in Europe is probably one of the main factors facilitating the development of chronic bronchitis in European farmers, and certain characteristics, such as indoor environmental dust concentration, may be specifically involved.

To conclude, asthma in farmers has been found to be partly related to poultry farming and flower growing, whereas chronic bronchitis seems to be related to pig and rabbit farming, and the cultivation of grain, oil-producing plants and flowers. The high prevalence of asthma in Californian farmers depends on sociodemographical factors rather than regional farming characteristics. In Europe, the high prevalence of chronic bronchitis in farmers is independent of smoking 
and seems to be only partly dependent on the type of animal and crop production practiced, but is clearly related to farming inside animal confinement buildings or greenhouses and indoor dust exposure. These findings suggest that indoor occupational exposure to animal and/or plant contaminants has a central role in the pathogenesis of chronic bronchitis in farmers.

\footnotetext{
Acknowledgements. The authors are grateful to the technicians who performed the field work and to M.E. Kerans for help in the preparation of the manuscript.
}

\section{References}

1. Kogevinas M, Antó JM, Sunyer J, et al. Occupational asthma in Europe and other industrialized areas: a population-based study. Lancet 1999; 353: 1750-1754.

2. Radon K, Danuser B, Iversen M, et al. Respiratory symptoms in European animal farmers. Eur Respir $J$ 2001; 17: 747-754.

3. Schenker MB, Christiani D, Cormier $\mathrm{Y}$, et al. Respiratory health hazards in agriculture. $A m J$ Respir Crit Care Med 1998; 158: Suppl. 5, 1-76.

4. Schwartz DA, Donham KJ, Olenchock SA, et al. Determinants of longitudinal changes in spirometric function among swine confinement operators and farmers. Am Respir Crit Care Med 1995; 151: 47-53.

5. Zejda JE, Hurst TS, Rhodes CS, Barber EM, McDuffie HH, Dosman JA. Respiratory health of swine producers. Focus on young workers. Chest 1993; 103: 702-709.

6. Jorna TH, Borm PJ, Valks J, Houba R, Wouters EF. Respiratory symptoms and lung function in animal feed workers. Chest 1994; 106: 1050-1055.

7. Iversen M, Dahl R. Working in swine-confinement buildings causes an accelerated decline in FEV1: a 7-yr follow-up of Danish farmers. Eur Respir J 2000; 16: 404408.

8. Vogelzang PFJ, Van der Gulden JWJ, Folgering H, et al. Endotoxin exposure as a major determinant of lung function in pig farmers. Am J Respir Crit Care Med 1998; 157: 15-18.

9. Donham KJ. Respiratory disease hazards to workers in livestock and poultry confinement structures. Semin Respir Med 1993; 14: 49-59.

10. Bessot JC, Blaumeiser M, Kopferschmitt MC, Pauli G. L'asthme professionnel en milieu agricole. Rev Mal Respir 1996; 13: 205-215.

11. Blaski CA, Clapp WD, Thorne PS, et al. The role of atopy in grain dust-induced airway disease. $A m J$ Respir Crit Care Med 1996; 154: 334-340.

12. Dalphin JC, Dubiez A, Monnet E, et al. Prevalence of asthma and respiratory symptoms in dairy farmers in the French province of the Doubs. Am J Respir Crit Care Med 1998; 158: 1493-1498.

13. Dosman JA, Graham BL, Hall D, Van Loon P, Bhasin P, Froh F. Respiratory symptoms and pulmonary function in farmers. J Occup Med 1987; 29: $38-43$.

14. Toren K, Horte LG. Asthma mortality and occupation in Sweden 1981-1992. Am J Ind Med 1997; 31: 678-681.

15. Donham KJ, Zavala DC, Merchant JA. Respiratory symptoms and lung function among workers in swine confinement buildings: a cross-sectional epidemiological study. Arch Environ Health 1984; 39: 96-101.

16. Malmberg P, Rask-Andersen A, Hoglund S, Kolmodin-Hedman B, Guersey JR. Incidence of organic dust toxic syndrome and allergic alveolitis in Swedish farmers. Int Arch Allergy Appl Immunol 1988; 87: 47-54.

17. Cuthbert OD, Jeffrey IG, McNeill HB, Wood J, Topping MD. Barn allergy among Scottish farmers. Clin Allergy 1984; 14: 197-206.

18. Heinonen OP, Horsmanheimo M, Vohlonen I, Terho EO. Prevalence of allergic symptoms in rural and urban populations. Eur J Respir Dis 1987; 152: Suppl. 1, 64 69.

19. Omland O, Sigsgaard T, Hjort C, Pedersen OF, Miller MR. Lung status in young Danish rurals: The effect of farming exposure on asthma-like symptoms and lung function. Eur Respir J 1999; 13: 31-37.

20. Vogelzang PFJ, Van der Gulden JWJ, Tielen MJM, Folgering H, Van Schayck CP. Health-based selection for asthma, but not chronic bronchitis, in pig farmers: an evidence-based hypothesis. Eur Respir J 1999; 13: 187-189.

21. Nowak D. Prevalence and risk factors for airway diseases in farmers. A new EC multicentre project. Ann Agric Environ Med 1994; 1: 81-82.

22. Monsó E, Magarolas R, Radon $\mathrm{K}$, et al. Respiratory symptoms of obstructive lung disease in European crop farmers. Am J Respir Crit Care Med 2000; 162: 1246-1250.

23. Farrar JA. Injuries and respiratory health among California farm operators. University of California, Davis, CA, USA, 1998 (PhD Thesis)

24. Nieuwenhuisen MJ, Schenker MB, Samuels SJ, Farrar JA, Green SS. Exposure to dust, noise, and pesticides, their determinants, and use of protective equipment among California farm operators. Appl Occup Environ Hyg 1996; 11: 1217-1225.

25. Burney PGJ, Chinn S. Developing a new questionnaire for measuring the prevalence and distribution of asthma. Chest 1987; 91: Suppl. 6, 79-83.

26. Burney PC, Luczynska C, Chinn S, Jarvis D. The European Community Respiratory Health Survey. Eur Respir J 1994; 7: 954-960.

27. Ferris BG. Epidemiology standardization project. Am Rev Respir Dis 1978; 118: 1-120.

28. Rylander R, Peterson Y, Donham KJ. Questionnaire evaluating organic dust exposure. Am J Ind Med 1990; 17: $121-126$.

29. Radon K, Danuser B, Iversen $\mathbf{M}$, et al. Air contaminants in different European farming environments. Ann Agric Environ Med 2002; 9: 41-48.

30. Borghetti C, Magarolas R, Badorrey I, Radon K, Morera J, Monso E. Sensitization and occupational asthma in poultry workers. Med Clin (Barc) 2002; 118: 251-255.

31. Hosmer DW, Lemeshow S. Applied logistic regression. New York, John Wiley and Sons, 1989.

32. Pauwels RA, Buist AS, Calverley PM, Jenkins CR, Hurd SS. The GOLD Scientific Committee. Global strategy for the diagnosis, management, and prevention of chronic obstructive pulmonary disease. NHLBI/WHO Global Initiative for Chronic Obstructive Lung Disease (GOLD) Workshop summary. Am J Respir Crit Care Med 2001; 163: 1256-1276.

33. Melbostad E, Eduard W, Magnus P. Chronic 
bronchitis in farmers. Scand Work Environ Health 1997; 23: 271-280.

34. Melbostad E, Eduard W, Magnus P. Determinants of asthma in a farming population. Scand $J$ Work Environ Health 1998; 24: 262-269.

35. Iversen M, Dahl R, Korsgard J, Hallas T, Jensen EJ. Respiratory symptoms in Danish farmers: an epidemiological study of risk factors. Thorax 1988; 43: 872877.

36. Dalphin JC. Chronic obstructive bronchitis in a fodder farming setting. Rev Mal Respir 1996; 13: 575-581.

37. Vergnenegre A, D'Arco X, Melloni B, et al. Workrelated distal airway obstruction in an agricultural population. Occup Environ Med 1995; 52: 581-586.

38. Gamsky TE, Schenker MB, McCurdy SA, Samuels SJ. Smoking, respiratory symptoms, and pulmonary function among a population of Hispanic farmworkers. Chest 1992; 101: 1361-1368.

39. Monsó E, Magarolas R, Badorrey I, Radon K, Nowak D, Morera J. Occupational asthma in greenhouse flower and ornamental plant growers. $A m J$ Respir Crit Care Med 2002; 165: 954-960.

40. Kimbell-Dunn M, Bradshaw L, Slater T, ErkinjunttiPekkanen R, Fishwick D, Pearce N. Asthma and allergy in New Zealand farmers. Am J Ind Med 1999; 35: 51-57.

41. Bar-Sela S, Teichtahl H, Lutsky I. Occupational asthma in poultry workers. J Allergy Clin Immunol 1984; 73: 271-275.

42. Lutsky I, Teichtahl H, Bar-Sela S. Occupational asthma due to poultry mites. $J$ Allergy Clin Immunol 1984; 73: 56-60.

43. Perfetti L, Cartier A, Malo JL. Occupational asthma in poultry-slaughterhouse workers. Allergy 1997; 52: 594-595.

44. Piirila P, Keskinen H, Leino T, Tupasela O, Tuppuraine M. Occupational asthma caused by decorative flowers: review and case reports. Int Arch Occup Environ Health 1994; 66: 131-136.

45. Janson C, Antó J, Burney P, et al. The European Community Respiratory Health Survey: what are the main results so far? European Community Respiratory Health Survey II. Eur Respir J 2001; 18: 598-611.

46. European Community Respiratory Health Survey. Variations in the prevalence of respiratory symptoms, self-reported asthma attacks, and use of asthma medication in the European Community Respiratory Health Survey (ECRHS). Eur Respir J 1996; 9: 687695.

47. Centers for Disease Control and Prevention. National Center for Health and Statistics. Vital and Health Statistics. Series 10, number 205.

48. Cerveri I, Accordini S, Verlato G, et al. Variations in the prevalence across countries of chronic bronchitis and smoking habits in young adults. Eur Respir $J$ 2001; 18: 85-92.

49. Zock JP, Sunyer J, Kogevinas M, et al. Occupation, chronic bronchitis and lung function in young adults. An international study. Am J Respir Crit Care Med 2001; 163: 1572-1577.

50. Wilhelmsson J, Bryngelsson IL, Ohlson CG. Respiratory symptoms among Swedish swine producers. Am J Ind Med 1989; 15: 311-318.

51. Dalphin JC, Bildstein F, Pernet D, Dubiez A, Depierre A. Prevalence of chronic bronchitis and respiratory function in a group of dairy farmers in the French Doubs province. Chest 1989; 95: 1244-1247.

52. Carvalheiro MF, Peterson Y, Rubenowitz E, Rylander R. Bronchial reactivity and work-related symptoms in farmers. Am J Ind Med 1995; 27: 65-74.

53. Dalphin JC, Pernet D, Dubiez A, Debieuvre D, Allemand H, Depierre A. Etiologic factors of chronic bronchitis in dairy farmers. Case control study in the Doubs region of France. Chest 1993; 103: 417-421.

54. Cormier Y, Boulet LP, Bedard G, Tremblay G. Respiratory health of workers exposed to swine confinement buildings only or to both swine confinement buildings and dairy barns. Scand J Work Environ Health 1991; 17: 269-275.

55. Vohlonen I, Tupi K, Terho EO, Husman K. Prevalence and incidence of chronic bronchitis and farmer's lung with respect to the geographical location of the farm and to the work of farmers. Eur J Respir Dis 1987; 152: Suppl 1, 37-46.

56. Dalphin JC, Debieuvre D, Pernet D, et al. Prevalence and risk factors for chronic bronchitis and farmer's lung in French dairy farmers. Br J Ind Med 1993; 50: 941-944.

57. Mauny F, Polio JC, Monnet E, et al. Longitudinal study of respiratory health in dairy farmers: influence of artificial barn fodder drying. Eur Respir J 1997; 10: $2522-2528$. 